\title{
Herbage characteristics and performance of steers grazing old world bluestem
}

\author{
SAMUEL W. COLEMAN AND T.D.A. FORBES
}

Author are research animal scientists, USDA-ARS, Grazinglands Research Laboratory, El Reno, Okla. 73036; and associate professor, Texas A\&M Research and Extension Center, Uvalde, Tex. 78801. At the time of the research, the junior author was research associate, Department of Animal Science, Oklahoma State University, Stillwater, Okla. Present address: Texas A\&M Research and Extension Center, I619 Garner Field Rd., Uvalde, Tex. 78801 .

\begin{abstract}
Old World bluestem (OWB; Bothriocloa spp.) are popular in the southern Great Plains but little is known about the relationships between forage characteristics and animal productivity. The influence of differences in herbage mass and sward height of OWB on rate of gain during the summer grazing season was examined during 2 years at El Reno, Okla. Soils were fine, silty Pachic Haplustolls of the Dale series. Swards of caucasian [B. caucasica (Trin.) C. E. Hubb.] and 'Plains' [B. ischaemum var ischaemum (L.) Keng.] OWB were maintained at different levels of forage mass (low, medium, and high) by continuous variable stocking and were grazed from mid- May to late September by steers with an initial weight of about $225 \mathrm{~kg}$. Weight gains were depressed in late August, but in 1985 gains recovered due to late season rains. Season-long gains averaged $0.61 \mathrm{~kg} \mathrm{day}^{-1}$ in 1984 and $0.69 \mathrm{~kg} \mathrm{day}^{-1}$ in 1985. Daily gains of steers increased linearly with increased herbage mass $(P<0.05)$, but slopes were different due to a year $X$ species interaction. Daily gains peaked at a herbage height of $41 \mathrm{~cm}$ in 1984, but increased linearly throughout the range of the data $(75 \mathrm{~cm})$ in 1985 . Individual animal gains decreased linearly with increasing stocking rate such that maximum gain per hectare was achieved at about 5 animals ha-1 (standard $500 \mathrm{~kg}$ ). The data suggest that maintaining higher herbage mass and height of $O W B$ forage improves animal performance and support the practice of intensive early grazing and removing cattle by late July when rate of gain declines.
\end{abstract}

Key Words: grazing pressure, herbage mass, herbage height, stocking rate, animal gains.

Millions of hectares of the Asiatic or Old World bluestem grasses have been planted in the Southern Great Plains as alternatives to native range, weeping lovegrass [Eragrostis curvula (Schrad.) Nees var. curvula Nees] and bermudagrass [Cynodon dactylon (L.) Pers.]. The Old World bluestems are perennial, warm-season bunch grasses with good productivity, persistence and drought tolerance (Taliaferro et al. 1972; Taliaferro et al. 1984). In 2 out of 3 years, Old World Bluestem (OWB) produced more beef per ha than either native range grasses or bermuda-

\footnotetext{
Reprint requests should be addressed to Samuel W. Coleman
}

Manuscript accepted 13 Sept. 1997. grass (Phillips and Coleman 1995), but at a higher cost than native range. In general, animal gains on all of the systems were moderate to poor ( 0.5 to $\left.0.75 \mathrm{~kg} \mathrm{day}^{-1}\right)$. 't Mannetje and Ebersohn (1980) stated that intake and animal production are asymptotically related to total dry matter in the pasture where the herbage consumed is a constant proportion of herbage present. Forbes and Coleman (1993) reported that maintaining $1 \mathrm{Mg} \mathrm{ha}^{-1}$ of green leaf mass maximized intake of OWB forage dry matter and digestible organic matter. Data that define the relationship of herbage mass or stocking rate to animal productivity are very limited for pastures composed of the tall bunchgrasses common to the Southern Great Plains, either in native stands or in sown pastures. The objective of this experiment was to determine how herbage mass and height influence rate of gain of steers grazing OWB and total productivity of the pastures.

\section{Materials and Methods}

The study was conducted at the USDA-ARS Grazinglands Research Laboratory at El Reno, Okla., $\left(35^{\circ} 33^{\prime} \mathrm{N}, 98^{\circ} 2^{\prime} \mathrm{W}, 423\right.$ m above sea level) during 1984 and 1985. Soils at the site were fine, silty Pachic Haplustolls of the Dale series. During each year, 200 yearling commercial crossbred beef steers predominantly of Hereford and Angus breeding were obtained from producers in the area, dewormed, vaccinated for respiratory pathogens and allowed to acclimate for 2 weeks. They were then weighed full and a uniform set $(227 \pm 21 \mathrm{~kg})$ by weight was selected for tester animals that were randomly assigned to pastures.

Fourteen experimental pastures ( 1.6 ha each) were seeded to either Plains or caucasian Old World Bluestem (OWB) in a completely randomized design in 1979. All pastures were cut for hay in 1980 and were grazed in 1981. During 1982 and 1983, each pasture was grazed at a similar intensity as in the current experiment (Forbes and Coleman 1993). All pastures were burned about 1 March each year and fertilized immediately with $80 \mathrm{~kg}^{-1}$ $\mathrm{N} \mathrm{ha}^{-1}$. Six of the pastures ( 3 for each species) were divided in half to produce twelve 0.8 ha pastures that were randomly allocated within species to 1 of 3 levels of herbage mass, designated low, medium and high projected at $1.5,3.0$ and $4.5 \mathrm{Mg}^{-1}$ herbage mass. The remaining 8 pastures ( $1.6 \mathrm{ha}$ ) were randomly assigned within species to the low or high herbage mass. Two tester animals grazed each 0.8 - ha plot and 4 testers grazed the 1.6- ha 
plots throughout the grazing season. The target herbage mass was maintained by the use of 'put and take' animals. Decisions regarding addition or removal of animals were based on weekly estimations of herbage mass and sward surface height.

\section{Sward Measurements}

Herbage mass was determined weekly with a single probe capacitance meter (Vickery et al. 1980; Vickery and Nicol 1982) calibrated monthly by hand clipped samples. Each week, 15 readings were taken at random within each quarter of the 0.8 -ha pasures and within each sixth of the 1.6- ha pastures. Before and after the 15 capacitance readings were taken, a reading was taken with the capacitance probe pointing into the air for correction (AIR). The capacitance taken with the probe in the herbage was subtracted from that in air for a corrected capacitance (Vickery and Nicol 1982). Calibration samples were clipped from two, 20 $\times 50 \mathrm{~cm}$ quadrats in each pasture to crown level and were dried in a forced air oven at $65^{\circ} \mathrm{C}$. Before clipping, 10 capacitance readings were taken from within the quadrat, starting $6 \mathrm{~cm}$ from the edge with an AIR correction before and after. Capacitance for the herbage was the difference between the 2 AIR readings $\times 5$ and the sum of the 10 readings taken from the herbage. Because the relationship of capacitance to dry yield was different each month, dry weight $\left(\mathrm{Mg} \mathrm{ha}^{-1}\right)$ was regressed on capacitance within each month to obtain prediction equations. The equations were then used to calculate herbage mass for each of the individual capacitance measurements for each pasture. Sward height $(\mathrm{cm})$ was measured at each spot for which a capacitance measurement was taken and was also averaged for each pasture.

\section{Animal Measurements}

All animals were weighed before and after each grazing season after an overnight fast without feed and water. Average rate of gain (shrunk) was calculated for each pasture as the final weight minus the initial weight divided by number of days. During the experiment, each animal was weighed full at approximately 28 day intervals. Additional animals (put-and-take) could be added at weekly intervals. Put-and-take animals were weighed on and off each pasture they grazed to calculate forage demand based on total animal weight per pasture per day.

In order to describe the pattern of gain over the grazing season unincumbered by treatment differences in fill, estimated shrunk weights throughout the grazing season were calculated by the following procedure. Full weights for each tester animal were regressed on days on trial with cuhic regression and full weights predicted for the initial and final date, when actual shrunk weights were taken. Fill was calculated for the initial and final date as the difference between actual shrunk weight and predicted full weight. Weighted fill differences were calculated for each weigh date and shrunk weights were calculated by subtracting fill from full weight with the assumption that changes in fill were linear over the grazing season. The calculated shrunk weights were regressed on days using cubic regression to obtain coefficients of growth through the grazing season.

\section{Statistical Analysis}

The season-long response variables were analyzed by analysis of variance computed as a completely randomized experiment, with 4 replicates of the low and high levels of herbage mass and 2 replicates for the medium. Year was a random main effect, herbage species and level of herbage were fixed main effects. Pasture was the experimental unit and herbage and animal measurements were averaged within each pasture. This design allowed 20 pasture observations for season-long measurements each year. For seasonal trends, sampling date was treated as a continuous variable (co-variate) of days from the beginning of the grazing season to evaluate the patterns of plant and animal growth. Analysis of covariance was also conducted by regressing season-long animal response on season-long average herbage mass and height and on stocking rate. The GLM procedure of SAS (1990) was used for all analyses.

\section{Results and Discussion}

Weekly average minimum and maximum temperature patterns were typical of those during the past 25 ycars at the location (Fig. 1). Annual precipitation was $8 \mathrm{~cm}$ less in 1984 and $13 \mathrm{~cm}$ greater in 1985 than the 25 -year average $(81 \mathrm{~cm})$, although the number of measurable precipitation events was similar for both years. In 1985 , late season rains resulted from a hurricane that accounted for most of the precipitation above the 25 -year average.

The relationship between herbage mass and capacitance was linear for June through August, 1984 (Fig. 2a-2c) and quadratic in September 1984 (Fig. 2d). Slopes of the linear terms were different $(P<0.05)$ among months and became steeper as the season progressed indicating that greater herbage mass was required for each increment of capacitance for the drier, more stemmy forage late in the scason. In Septembcr, the curve resembled an expo-

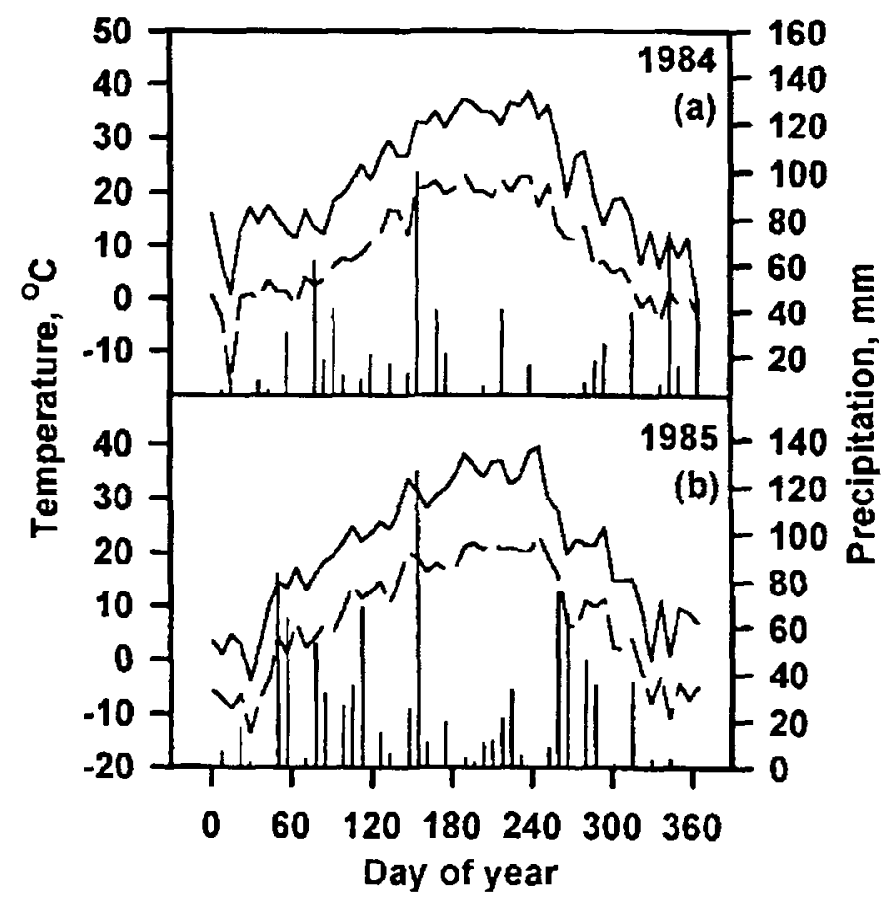

Fig. 1. Minimum and maximum daily temperatures and amount of precipitation during 1984 (a) and 1985 (b). Vertical bars are amount of precipitation each week of the year. 
nential. In 1985, equations for all months had significant quadratic components (Fig. $2 \mathrm{e}-2 \mathrm{f}$ ), and the differences among months were less striking. The coefficients were similar ( $P>0.05$ ) during July and August. The shape of the curve in 1985 (negative quadratic term) was similar to that reported by Vickery and Nicol (1982). In general, slopes were not as steep as in 1984, probably due to better control over the standing herbage mass. The slope differences indicate the necessity of frequent recalibration and the use of double sampling.

All variables describing the sward and animal response are shown in Tables 1 and 2 , and were different due to years and targeted herbage mass $(P<0.05)$. An interaction of year by targeted herbage mass was present $(P<0.05$ ) for measured herbage mass, herbage height, adjusted stocking rate, and animal days (Table 1). Herbage mass ranged from 2.7 to $8.6 \mathrm{Mg} \mathrm{ha}^{-1}$, higher than the targeted levels of 1.5 to $4 \mathrm{Mg}$ ha $^{-1}$. Herbage mass at the targeted high and medium levels was greater in 1984 than in 1985, but pastures at the low levels of targeted herbage mass were similar for both years $(\mathrm{P}>0.05$ ). In 1985 , there were no differences in measured herbage mass between high and medium target levels. In an experiment where 1 of the controls (herbage mass) is a measured variable, it is impossible to truly replicate the treatment. Therefore, a better approach is to use the individual pastures as observations, and use herbage mass or height as a covariate to determine the input-output relationships between the sward characteristics and animal response.

Herbage height was highly correlated with herbage mass $(r=0.95)$, but the relationship was slightly curvilinear and differed between years $(P<0.01$; data not

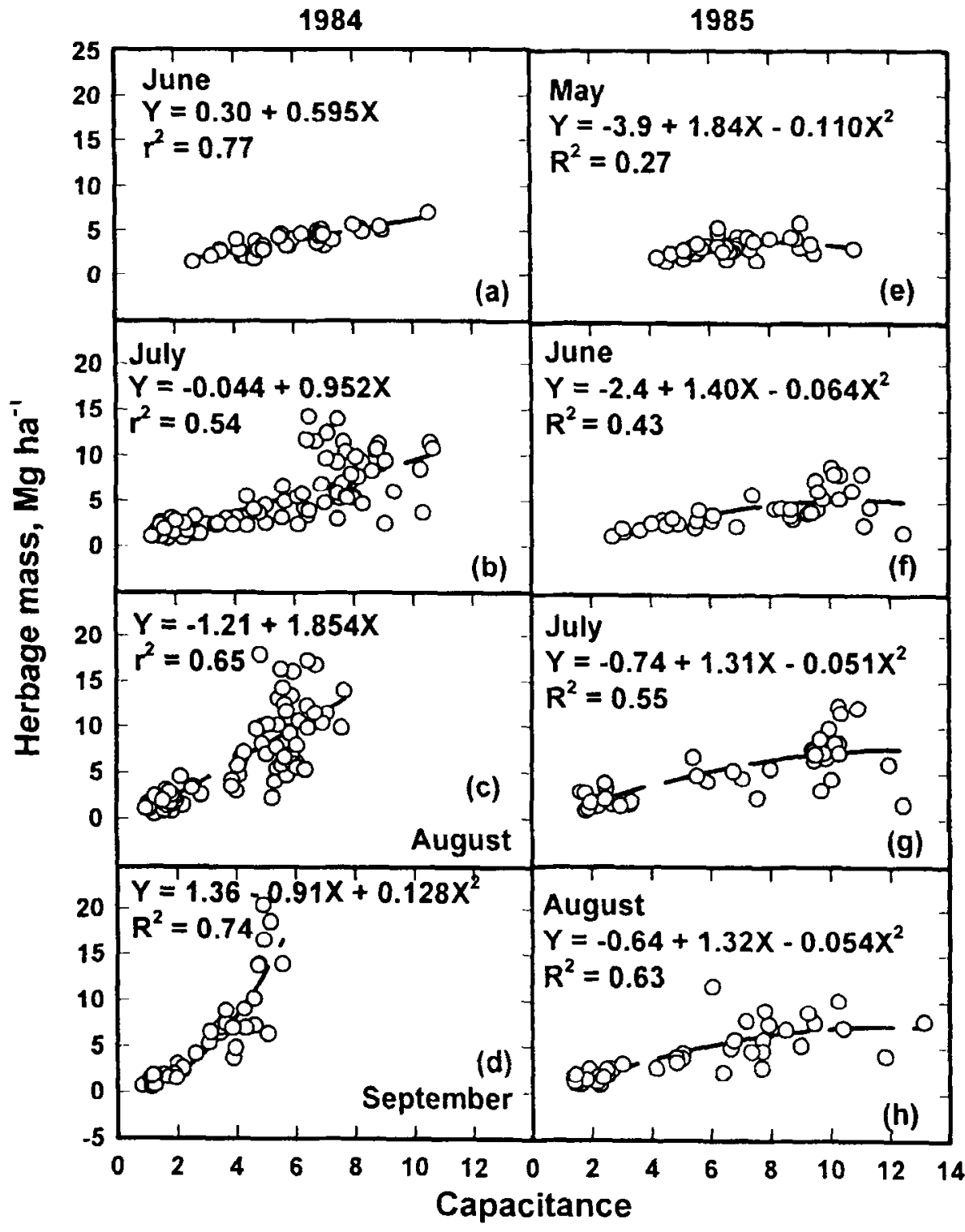

Fig. 2. Relationship of capacitance from pasture probe and herbage mass for each month of the grazing season.

Table 1. Season-long averages for herbage characteristics and animal performance by year and targeted level of herbage mass ${ }^{1}$.

\begin{tabular}{|c|c|c|c|c|c|c|c|}
\hline \multirow[b]{2}{*}{ Item } & \multicolumn{3}{|c|}{1984} & \multicolumn{3}{|c|}{1985} & \multirow[b]{2}{*}{ SE } \\
\hline & $\mathrm{High}^{2}$ & Medium & Low & High & Medium & Low & \\
\hline Herbage mass, $\mathrm{Mg} \mathrm{ha}^{-1}$ & $8.64^{\mathrm{d} 3}$ & $6.63^{\mathrm{c}}$ & $2.89^{\mathrm{a}}$ & $4.98^{b}$ & $4.68^{b}$ & $2.67^{a}$ & 0.21 \\
\hline Herbage height, $\mathrm{cm}$ & $64.3^{d}$ & $41.8^{b c}$ & $11.5^{\mathrm{a}}$ & $43.3^{c}$ & $35.6^{\mathrm{b}}$ & $14.1^{\mathrm{a}}$ & 2.1 \\
\hline Average daily gain, $\mathrm{kg}$ & $0.69^{b}$ & $0.62^{b}$ & $0.51^{a}$ & $0.75^{d}$ & $0.79^{d}$ & $0.54^{c}$ & 0.04 \\
\hline Average stocking rate an ha $\mathrm{h}^{-1}$ & $3.01^{\mathrm{a}}$ & $4.79^{b}$ & $6.90^{c}$ & $5.24^{b}$ & $5.41^{b}$ & $8.53^{d}$ & 0.28 \\
\hline $\begin{array}{l}\text { Average adjusted stocking rate } \\
500 \mathrm{~kg} \mathrm{ha}^{-1}\end{array}$ & $1.64^{a}$ & $2.76^{\mathrm{b}}$ & $3.80^{c}$ & $2.98^{b}$ & $3.06^{\mathrm{b}}$ & $4.78^{d}$ & 0.17 \\
\hline Animal days & $341^{\mathrm{a}}$ & $607^{b}$ & $745^{c}$ & $612^{b}$ & $624^{b}$ & $1065^{d}$ & 36 \\
\hline Adjusted animal days, $500 \mathrm{~kg}$ & $192^{\mathrm{ca}}$ & $360^{6}$ & $416^{b}$ & $362^{b}$ & $370^{\mathrm{b}}$ & $620^{\mathrm{c}}$ & 22 \\
\hline Season-long gain, $\mathrm{kg} \mathrm{ha}^{-1}$ & $234^{\mathrm{a}}$ & $387^{b}$ & $359^{b}$ & $450^{c}$ & $496^{d}$ & $582^{d}$ & 34 \\
\hline
\end{tabular}

${ }^{\text {Least square means }}$

${ }^{2} \mathrm{High}$, medium, and low levels of target herbage mass; $\mathrm{SE}=$ standard error

${ }^{3}$ Means in the same row with different superscripts are different $(\mathrm{P}<0.05)$ 
Table 2. Season-long averages for herbage characteristics and animal performance by species and targeted level of herbage mass 1 .

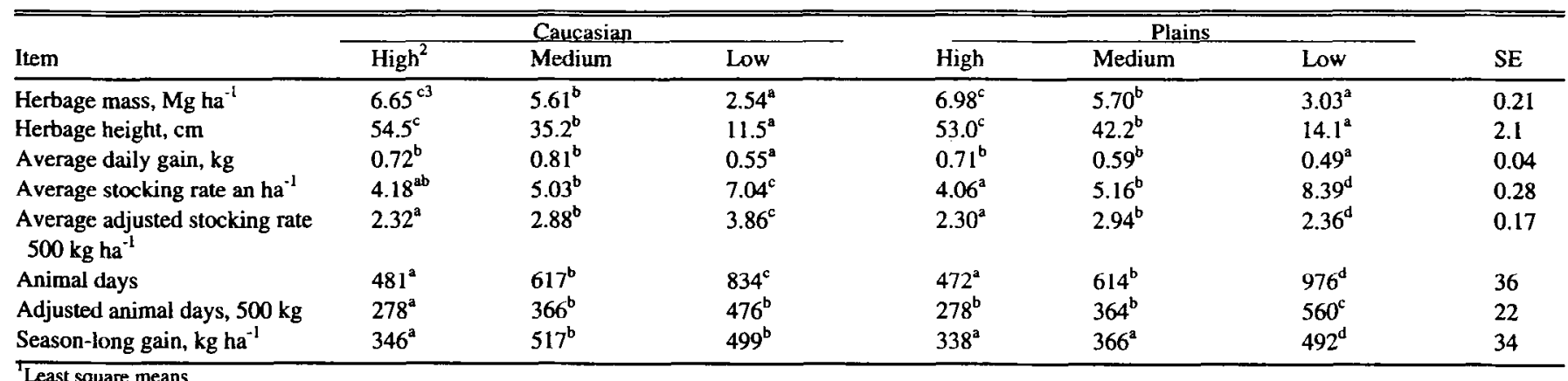

Least square means

${ }^{2}$ High, medium, and low levels of target herbage mass; SE = standard error

${ }^{3}$ Means in the same row with different superscripts are different $(P<0.05)$.

shown). Sward height of pastures increased $(P<0.05)$ with increasing levels of targeted herbage mass. Pastures maintained at high herbage mass were stocked with the minimum 2.5 steers ha ${ }^{-1}$ throughout the season in 1984 with very little change in stocking rate. As a result, these pastures were heavily 'spot-grazed' with much of the land area not being grazed at all. As the season progressed, the grazed areas were heavily utilized and slowly expanded to provide additional forage as the growth rate subsided. All pastures were stocked heavier in 1985 than in 1984, thus, resulting in lower and more uniform herbage mass and height at the medium and high target levels.

Herbage mass and height were quite variable during the course of the grazing season (Fig. 3 and 4, respectively). During both years, the pastures were similar at the start of the season because all animals were moved onto the pastures at the same time. In retrospect, a better alternative might have been to start those animals assigned to the pastures targeted for low herbage mass earlier, but weight gains and forage growth during that time would have been confounded. In 1984, herbage mass was already at $4.4 \mathrm{Mg} \mathrm{ha}^{-1}$ at the initiation of grazing and growth rate was very rapid. In 1985 , grazing was initiated earlier with about $3.5 \mathrm{Mg}^{-1}$ and growth occurred much more slowly with pastures at high and medium herbage mass exhibiting very similar growth patterns. The model GRAZE (Smith and Loewer 1983) predicted that the amount of accumulated above-ground dry matter that provides enough leaf area to support the maximum growth rate (Seman et al. 1995) was $2.3 \mathrm{Mg} \mathrm{ha}^{-1}$. Projected growth rate was $254 \mathrm{~kg} \mathrm{ha}^{-1}$ day $^{-1}$ (Coleman et al. 1995b) and represents the amount that could be harvested without diminishing growth rate. Thus the model suggests that grazing should be initiated when herbage mass reaches about 2.3 $\mathrm{Mg} \mathrm{ha}^{-1}$ with a harvest rate of $254 \mathrm{~kg} \mathrm{ha}^{-1}$ day $^{-1}$. Linear and quadratic regression equations published by Dabo et al. (1987), upon whose data the model was parameterized, indicated that only 56 to $100 \mathrm{~kg} \mathrm{ha}^{-1}$ day $^{-1}$ forage would be produced. However, the

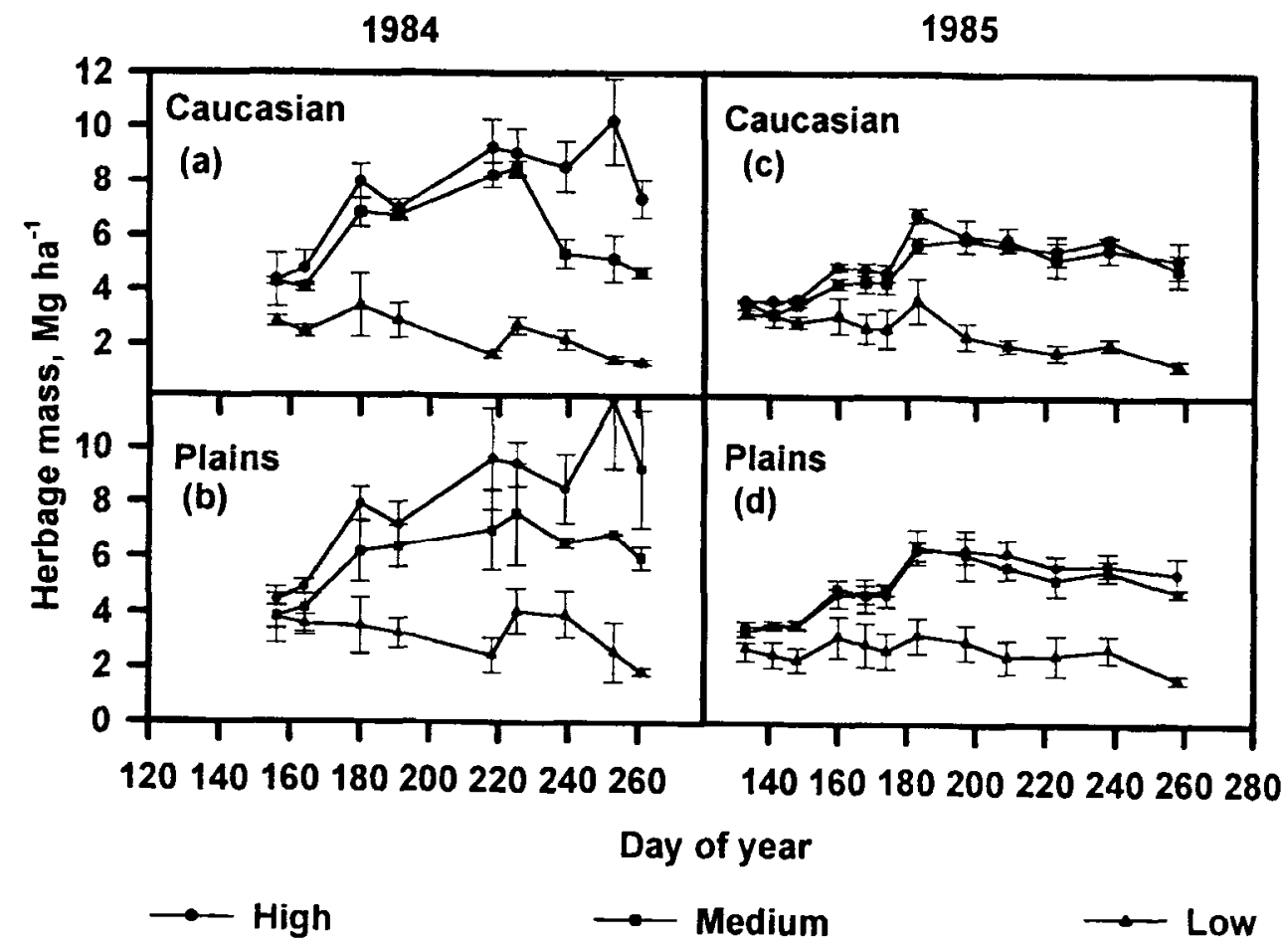

Fig. 3. Patterns of actual herbage mass over the grazing season as influenced by forage species and level of targeted herbage mass (high, medium, and low) in 1984 (a and b) and in 1985 (c and d). Vertical bars represent standard deviations. 


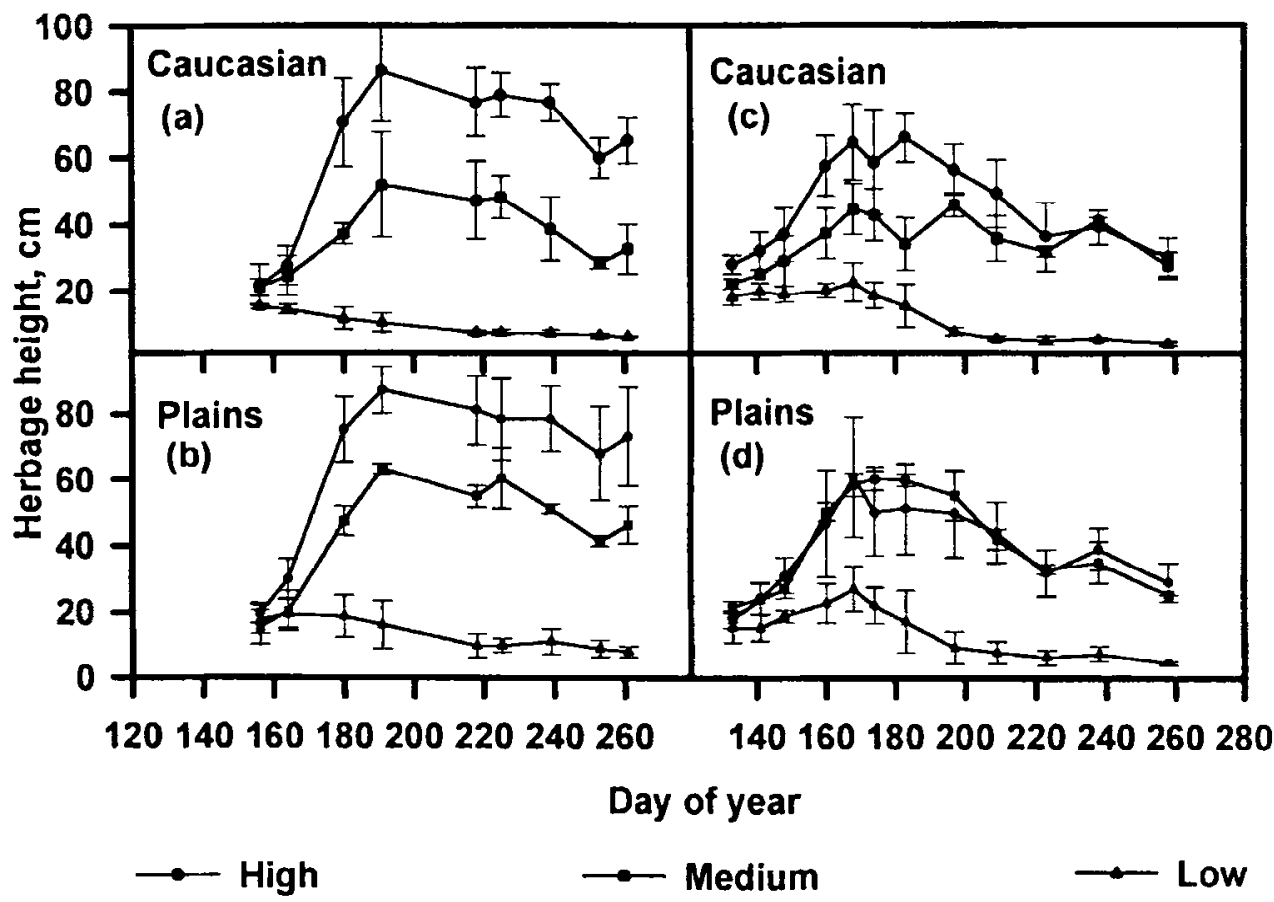

Fig. 4. Patterns of herbage height over the grazing season as influenced by level of targeted herbage mass (high, medium, and low) in 1984 (a and b) and in 1985 (c and d). Vertical bars represent standard deviations.

regression equations would reflect an average growth rate over the 13-week growing season, not the maximum rate.

Herbage height was similar at initiation of grazing for both years. Swards with high and medium herbage mass increased rapidly in height and then declined due to harvesting by the animals and decreasing rate of plant growth. The greater herbage mass, but not height, at the beginning of 1984, compared with 1985 , could be due to greater tiller number and weight as a result of the delayed start date for grazing.

Averaged over the grazing season, daily gain was higher for pastures with high and medium levels of herbage mass than for those with low levels (Table 1). Caucasian supported higher gains than Plains in 1984 ( 0.69 vs $0.52 \mathrm{~kg}$ day $^{-1} ; \mathrm{P}<0.05$; Table 2 ). Both species supported similar gains in 1985 (0.69 kg day $\left.{ }^{-1}\right)$. Patterns of animal weight during the growing season are shown in Fig. 5 and 6 for 1984 and 1985, respectively. A 3-way interaction for intercepts among years, forage species, and herbage mass occurred, thus, separate analyses were conducted for each year. In 1984, weight patterns were typical of those produced by warm season perennial grasses, with an obvious summer slump during August (day 214-243). In 1985, weight patterns also demonstrated the typical summer slump, but late season precipitation allowed short-term gains during the last weigh period.

Instantaneous rate of gain for any given date can be determined from the first derivative of the function describing weight with time. From this function, rate of gain in 1984 declined linearly during the grazing season and was 0 at 260 days (20 September) for all caucasian and for Plains bluestem pastures with high and low herbage mass. Rate of gain was 0 by 241 days for Plains bluestem managed for medium herbage mass. In 1985, the late season surge in weight gain after 1 September (245th day) result- ed in a cubic regression and salvaged the summer slump, but gains were minimal from day 200 (18 July) until September. During both years, gains were very rapid early in the season when forage supply was plentiful and nutritious. These data would support the suggestion that intensive early grazing would provide essentially the same total gain per animal as season-long grazing, but in a shorter time period and likely at a higher stocking rate. Utilizing the growth curves and current economic conditions such as seasonal livestock prices, producers could project the most profitable time to market. The use of regression to determine patterns of gains over the season provides a better understanding for grazing Old World Bluestem (OWB) and probably other warm season perennial grasses than season-long average daily gains alone.

Season-long average daily gain (ADG) is plotted against average herbage mass in Figure 7. A year $\times$ species interaction occurred for the slopes and intercepts, so separate analyses were conducted for each year. In 1984, caucasian bluestern supported greater season-long gains and little change $(P>0.05)$ was noted from 2.5 to $6.5 \mathrm{Mg} \mathrm{ha}^{-1}$ in herbage mass. Rate of gain for Plains pastures, however, increased $0.054 \mathrm{~kg} \mathrm{day}^{-1}$ for each $\mathrm{Mg}$ increase in herbage mass $\left(r^{2}=0.76 ; P<0.05\right)$. The difference between species may be a difference in growth form. Caucasian bluestem grows more upright, whereas Plains tends to be more prostrate, especially under close grazing (Forbes and Coleman 1993). At reduced herbage mass, individual tillers of caucasian plants would be taller and grazing animals could more readily prehend and consume forage than from the more prostrate Plains plants. In 1985, data from both species fit a common regression in which ADG increased $0.085 \mathrm{~kg}$ for each $\mathrm{Mg}$ in available herbage $\left(\mathrm{r}^{2}=\right.$ $0.49 ; \mathrm{P}<0.05$ ). Also, all gains were higher in 1985 than in 1984 , 


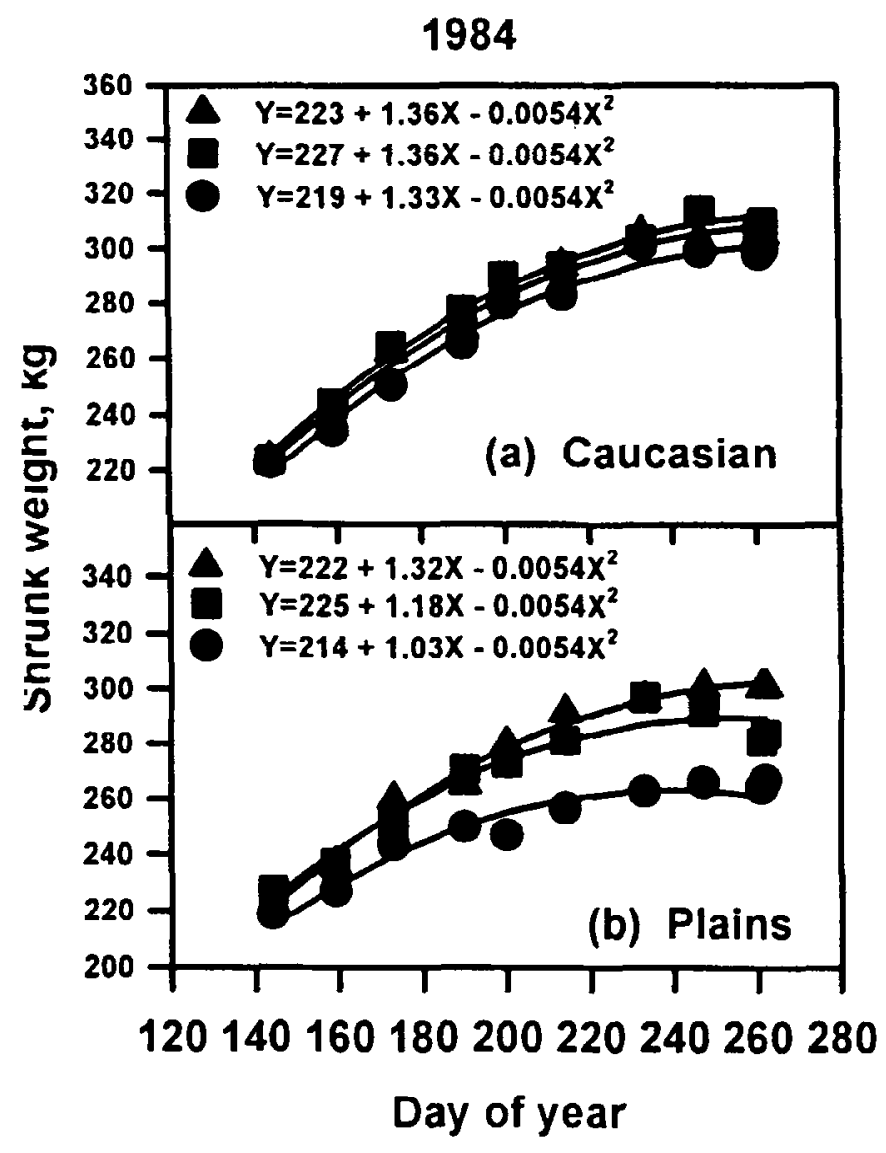

\section{$\triangle$ High D Medium Low}

Fig. 5. Patterns of animal weights over the 1984 grazing season for different targeted levels of herbage mass (high, medium, and low) for caucasian (a) and Plains (b) Old World bluestem. Regression equations are based on days on test (23 May to 18 Sept.; 23 May = day 0 for the equations). $R^{2}$ for the model $=0.75$.

primarily due to the late season recovery (see Fig. 5 and 6). Hodgson (1982a) showed that daily herbage intake and intake per bite of continuously stocked swards of ryegrass [Lolium perenne (L.)] increased with increasing herbage mass, up to $2 \mathrm{Mg} \mathrm{ha}^{-1}$, the limits of the experimental conditions. 't Mannetje and Ebersohn (1980) suggested that when herbage consumed is not a fixed proportion of herbage present, such as when the pasture contains a seasonally variable amount of stem or dead material, intake or rate of gain (production) is asymptotically related to green herbage present. This situation should apply in the current study, but the proportion of green herbage was not measured. In an earlier study on some of the same pastures, Forbes and Coleman (1993) found that green leaf mass was more closely related to organic matter intake and digestible organic matter intake than other sward characteristics, primarily due to its influence on bite size. Dabo et al. (1987) reported that the leaf-to-stem ratio of OWB decreased from about 2 at 3 weeks regrowth to 0.5 at 13 weeks regrowth.

The relationship of season-long ADG to herbage height was different $(P<0.05)$ between species (Fig. 8a,b) and the intercepts were influenced by an interaction of species and years. The intercept and, therefore, overall gains were higher $(P<0.05)$ in 1985 for Plains bluestem whereas there were no differences between

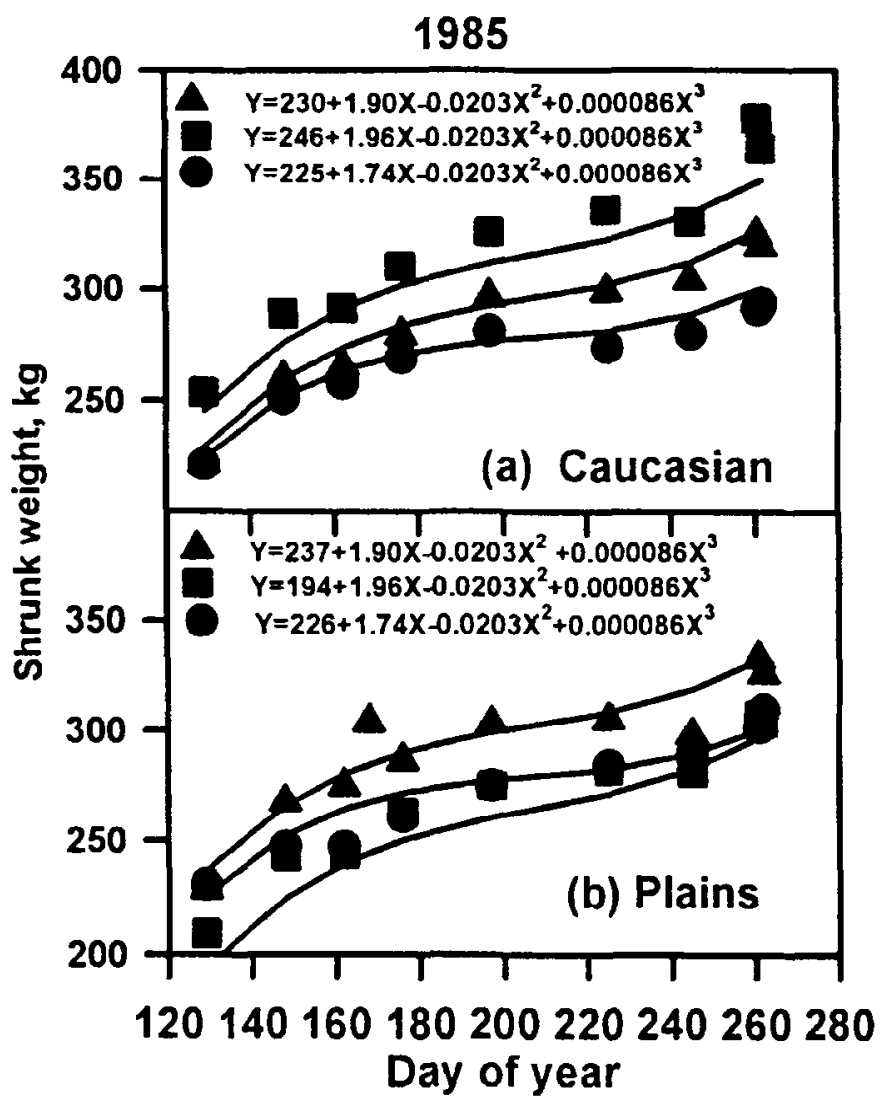

\section{$\Delta$ High $\square$ Medium Low}

Fig. 6. Patterns of animal weights over the 1985 grazing season for different levels of targeted herbage mass (high, medium, and low) for caucasian (a) and Plains (b) Old World bluestem. Regression equations are based on days on test $(9$ May to 19 Sept.; 9 May $=$ day 0 for the equations). $R^{2}$ for the model $=0.58$.

years for caucasian. Though equations for both species contain a quadratic component, only the one for caucasian was important for the range of the data in this study. Maximum gains for caucasian occurred at $41.7 \mathrm{~cm}$, slightly above the average height (35.2) of swards managed for medium herbage mass. Gains of steers grazing Plains bluestem continued to increase through the range of the data, influenced heavily by the lower and more linear relationship in 1984 than in 1985 . Previous research from Scotland with perennial ryegrass (Hodgson 1982b; Penning 1985) and from Australia (Black and Kenney 1984) suggested intake of sheep was related asymptotically to herbage height. The work of Hodgson (1982b) indicated that intake increased with increasing herbage height up to $30 \mathrm{~cm}$, but above $30 \mathrm{~cm}$, no further increases were observed. The current data suggests a maximum at 41.7 $\mathrm{cm}$, slightly taller than that of Hodgson (1982b), but much taller than the $6 \mathrm{~cm}$ at which Penning (1985) observed no additional response. The differences probably reflect the contrasting grazing habits of sheep and cattle (Forbes and Hodgson 1985), differences in the growth habits of perennial ryegrass and the Old World Bluestem (OWB) or to response differences of intake to height versus Average Daily Gain (ADG) to height. The OWB are tall, bunch grasses and the swards likely are different from perennial ryegrass in live- to-dead and leaf- to- stem ratios. Black 


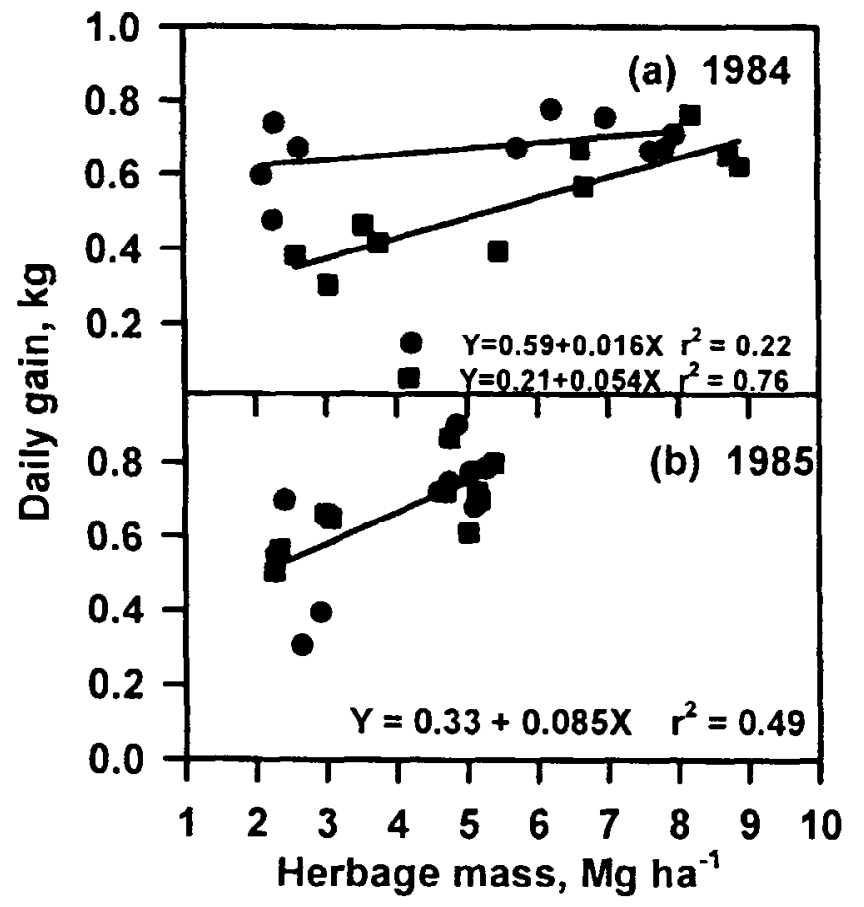

- Caucasian

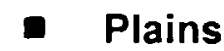

Fig. 7. Relationship of season-long average daily gain to season-long average herbage mass in 1984 (a) and 1985 (b).

and Kenney (1984) noted that both sward height and tiller density influenced intake rate of artificial swards. They found that intake rate reached a maximum at $6 \mathrm{~cm}$ sward height with 26,000 tillers $\mathrm{m}^{-2}$ but increased linearly to $20 \mathrm{~cm}$ with 1,600 tillers $\mathrm{m}^{-2}$. Stobbs (1973b) found that cows prehended a bite of maximum size when swards contained the highest proportion of accessible leaf. Stobbs (1973a) suggested that with tropical species, bite size could become so limiting that dairy cows could not consume enough digestible organic matter in a day to sustain production. Guerrero et al. (1984) showed that rate of gain on bermudagrass was asymptotically related to forage available per animal, but the curves were different for swards of different digestibility. The current data could be forced into an asymptotic equation with a resulting $r^{2}$ of 0.31 for all data. The quadratic equation presented for Caucasian in which gains were reduced when herbage height exceeded $42 \mathrm{~cm}$ could be explained by reduced forage quality at higher herbage height, or decreased leaf density (Stobbs 1973a). On the swards managed for high herbagc mass, particularly in 1984, the animals restricted themselves to small areas by patchy grazing and did not graze outside those areas late in the season when ungrazed plants had matured. Since our measurements were the average for an entire pasture, they included the taller ungrazed herbage, and did not necessarily reflect the height of the grazed horizon.

The general lack of fit (low $R^{2}$ ) between season-long ADG and average herbage mass or height can be attributed to variations in both dependent and independent variables over the course of the grazing season. For instance, all pastures produced excellent gains $\left(\sim 2 \mathrm{~kg} \mathrm{day}^{-1}\right)$ during the early part of the grazing season, but the production of forage and its quality declincd during July
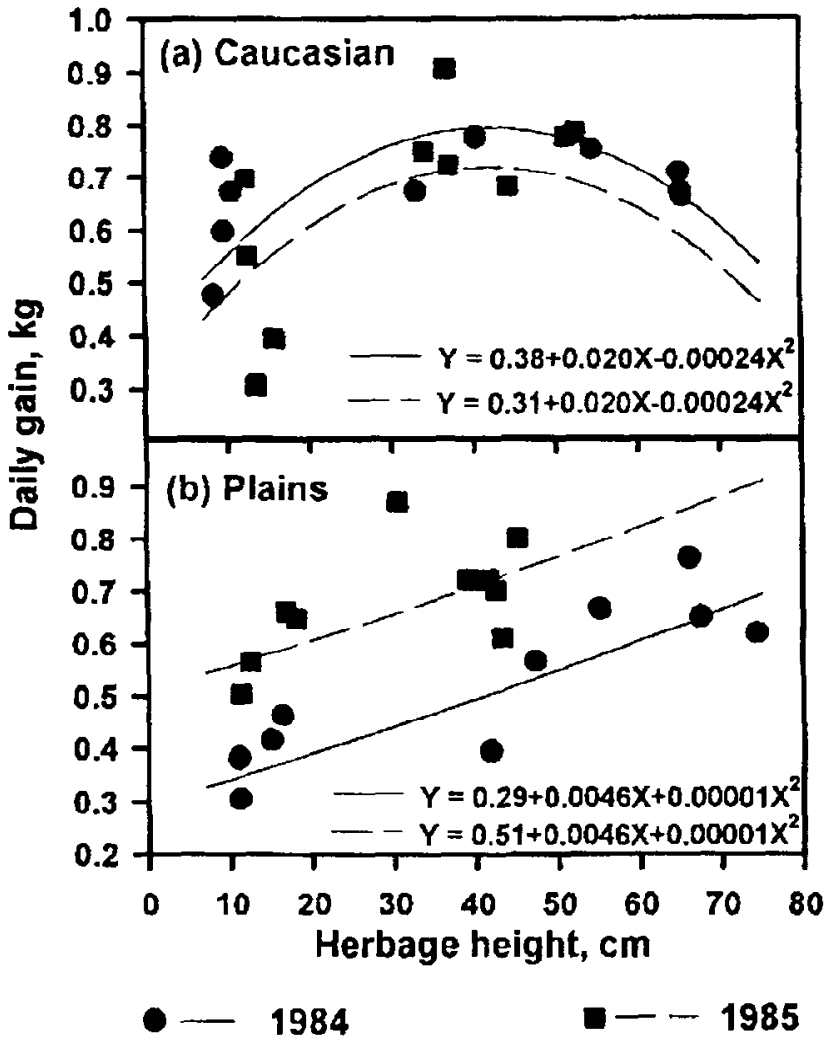

1985

Fig. 8. Relationship of season-long average daily gain to average herbage height for caucasian (a) and Plains (b) bluestem. $\mathbf{R}^{2}$ for the model $=0.67$.

and August so that animal gains became zero. These limitations to grazing trials have long been known and are a good reason to develop measurements or predictors of performance that can be obtained over short periods of time. The use of bite size to estimate intake (Stobbs 1973a, 1973b) is such a measure but requires animals cannulated at the esophagus or rumen to collect samples of the diet over a prescribed period of time. More recent efforts to estimate intake (Coleman et al. 1989; Coleman et al. 1995a) and diet quality (Coleman et al. 1989; Lyons and Stuth 1992) include analysis of feces using near-infrared reflectance spectroscopy. This technique has the potential to provide frequent estimates of digestible dry matter intake of free ranging animals which can be used in decision aids for producers.

Average stocking rate and total gain ha ${ }^{-1}$ for the season across years and levels of herbage mass are shown in Table 1 and across species and levels of herbage mass in Table 2. A 3-way interaction for year $x$ species $x$ herbage mass was present $(P<0.05)$ for stocking rate and adjusted animal days (data not tabulated). The interaction for stocking rate occurred because caucasian pastures managed for low herbage mass averaged 5.5 animals in 1984 and 8.6 in 1985 while Plains supported 8.4 animals in both years. Pastures managed for medium herbage mass averaged 5 animals $\mathrm{ha}^{-1}$ across years and species, whereas, those managed for high herbage mass supported 3 animals in 1984 and 5.2 in 1985. Adjusted animal days followed similar trends. The adjustment for stocking rate and animal days was to a standard $500 \mathrm{~kg}$ animal.

There was a negative linear relationship between rate of gain and stocking rate (Fig. 9a). This function has previously been 


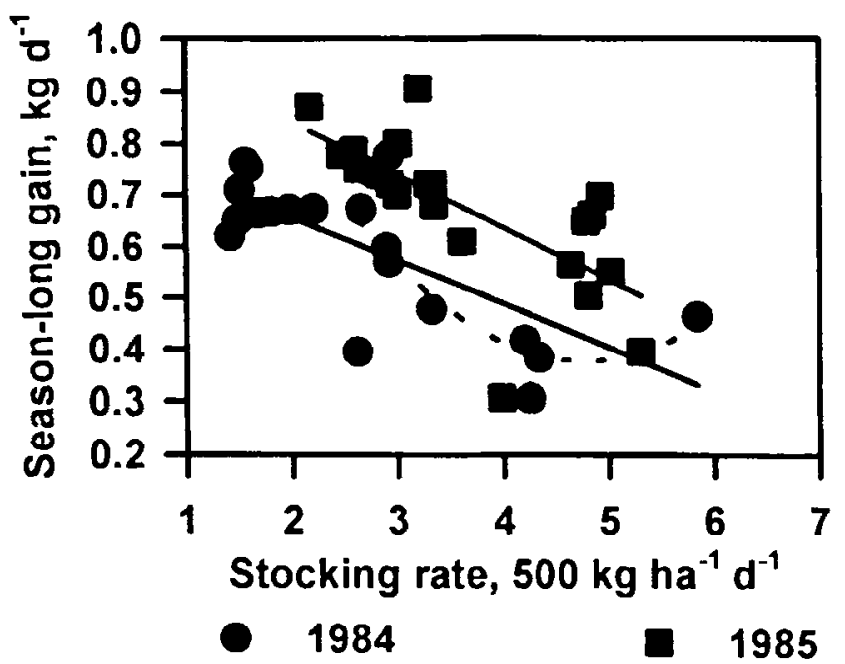

Fig. 9. Relationship of season-long average daily gain (a) and of total gain per hectare (b) to average stocking rate of a standard $500 \mathrm{~kg}$ animal. $Y=0.83-0.085 X$ for $1984\left(R^{2}=0.51\right)$ and $Y .05-0.48 X$ for $1985\left(R^{2}=0.48\right)$. Dotted line represents 1984 data above $2.5 \mathrm{~cm}$ in height: $=1.76-0.58 X+0.061 X^{2}\left(R^{2}=0.46\right)$.

described as a linear decline in ADG with increasing stocking rate (Jones and Sandland 1974; Sandland and Jones 1975), a curvilinear decline (Mott 1960) or a linear decline after a plateau at low stocking rates (Hart et al. 1988). For the current data, the quadratic expression was not significant $(P>0.05)$ and the intercepts for the equations were different for the 2 years. In 1984, however, gain appeared to plateau at about $0.7 \mathrm{~kg}$ day $^{-1}$ from 1 to.5 animals $\mathrm{ha}^{-1}$ (standard $500 \mathrm{~kg}$ animal), then declined hyperbolicly (Fig. 9, dotted line). Hart (1978) gave good theoretical evidence for this type of relationship at an instantaneous moment during the grazing season. However, as the season progressed, a family of similarly shaped curves occurred, with those later in the grazing season shifted downward at lower rates of gain due to
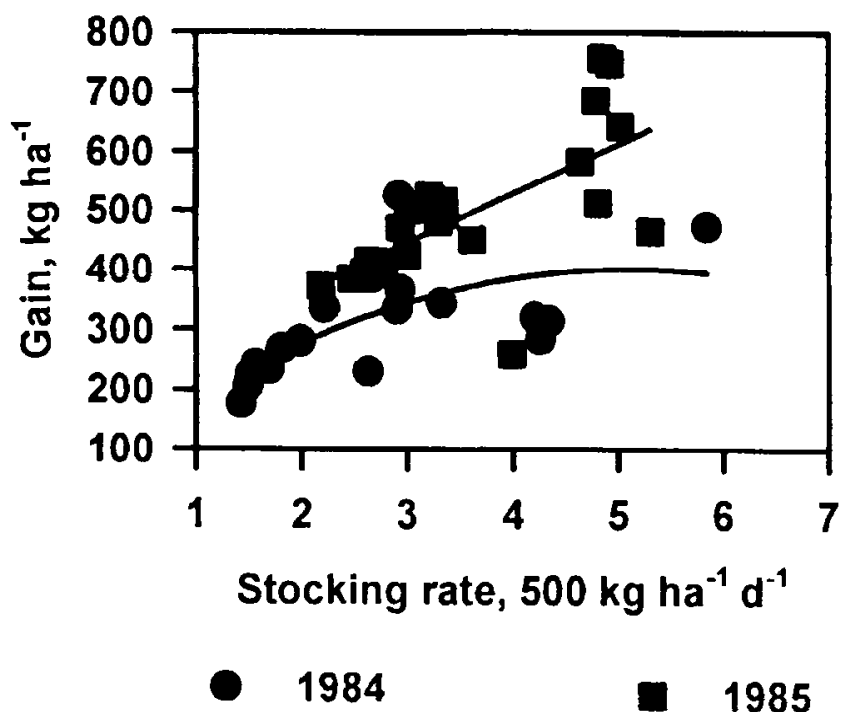

1985

Fig. 10. Relationship of total gain per hectare to average stocking rate. Regression equations are: $Y=70.1+129 X-12.5 X^{2}$ for 1984 $\left(R^{2}=0.43\right)$ and $Y=192+86 X-0.37 X^{2}$ for $1985\left(R^{2}=0.43\right)$. lower forage quality. He reasoned that when season-long gains were considered. the resultant 'average' relationship of all the curves was approximately linear. Since in 1984, the current data appear to follow Hart's theoretical curve, it is possible that using the put and take method to maintain swards at a given level provided a relationship that is more like the theoretical curve for an instantaneous moment in time rather than the average that would be obtained with set stocking rates over the grazing season.

If the function for ADG vs stocking rate $(X)$ is assumed to be linear, then the function for total gain ha ${ }^{1}(G)$ can be obtained (if $A D G=a-b X$, then $G=X^{*} A D G=a X-b X^{2}$; Mott 1960; Jones and Sandland 1974). Using this formula, the stocking rate calculated for these pastures achieved a maximum productivity per ha at about 5 standard $500 \mathrm{~kg}$ animals in 1984 and at 6 in 1985. The actual data (Fig 10) indicate a maximum production at 5 animals in 1984, but in 1985, gain increased linearly throughout the range of the data.

\section{Summary}

Old World bluestem forages are capable of supporting excellent gains early in the summer grazing season but that capability declines in late summer. Pastures should be managed for 5 or 6 $\mathrm{Mg}$ herbage $\mathrm{ha}^{-1}$, or about $40 \mathrm{~cm}$ in height, to optimize gain per steer. This will result in spot grazing and perhaps some inefficiency of harvesting, but should optimize gain per steer and maintain good residual leaf area for plant regrowth. Residual forage from spot grazing can be harvested by animals with lower targeted performance (such as dry cows) stocked at high rates.

\section{Literature Cited}

Black, J. L. and P. A. Kenney. 1984. Factors affecting diet selection by sheep. II. Height and density of pasture. Aust. J. Agr. Res. 35:565-578.

Coleman, S. W., J. W. Stuth, and J. W. Holloway. 1989. Monitoring the nutrition of grazing cattle with near-infrared analysis of feces. p. 881-882. In: Proc. XVI Int. Grassl..Congress.. Nice, France

Coleman, S. W., J. W. Stuth and J. W. Holloway. 1995a. Prediction of intake by near-infrared spectroscopic analysis of fecal samples. $p$. 145-155. In: F. N. Owens, D. Gill, K. Lusby, and T. McCollum (ed.). Symposium:Intake by Feedlot Cattle. Okla. Agr. Exp. Sta. Bull. P-942.

Coleman, S. W., C. M. Taliaferro and S. M. Dabo. 1995b. Case study 4: Forage production using old world bluestem grasses in the southern Great Plains. p. 23-26. In: O. J. Loewer and D. Parsch (ed.). GRAZE beef-forage simulation model:Case studies. Snuthern Cooperative Series Bull. 381B.

Dabo, S. M., C. M. Taliaferro, S. W. Coleman, F. P. Horn and P. L. Claypool. 1987. Yield and digestibility of old world bluestem grasses as affected by cultivar, plant part, and maturity. J. Range Manage. 40:10-15.

Forbes, T. D.A. and S. W. Coleman. 1993. Forage intake and ingestive behavior by cattle grazing Old World Bluestems. Agron. J. 85:808-816.

Forbes, T. D. A. and J. Hodgson. 1985. Comparative studies of the influence of sward conditions in the ingestive behaviour of cows and sheep. Grass Forage Sci. 40:69-77.

Guerrero, J. N., B. E. Conrad, E. C. Holt and H. Wu. 1984. Prediction of animal performance on Bermudagrass pasture from available forage. Agron. J. 76:577-580.

Hart, R. H. 1978. Stocking rate theory and its application to grazing on rangelands. p. 547-550. In: D. N. Hyder (ed.). Proc. 1st. Internat. Range. Congr. Soc. for Range Manage., Denver, Colo. 
Hart, R. H., J. W. Waggoner, Jr., T. G. Dunn, C. C. Kaltenbach, and L. D. Adams. 1988. Optimal stocking rate for cow-calf enterprises on native range and complernentary improved pastures. J. Range Manage. $41: 435-441$.

Hodgson, 1982a. Ingestive behaviour. p. 113-138. In: J. D. Leaver (ed.). Herbage intake handbook. British Grassl. Soc., Hurley, UK.

Hodgson, 1982b. Influence of sward characteristics on diet selection and herbage intake by the grazing animal. p. 153-66. In: J. B. Hacker (ed.). Nutritional limits to animal production from pastures. CAB, Slough, UK.

Jones, R. J. and R. L. Sandland. 1974. The relation between animal gain and stocking rate. Derivation of the relation from the results of grazing trials. J. Agr. Sci., Camb. 83:335-342.

Lyons, R. K. and J. W. Stuth. 1992. Fecal NIRS equations for predicting diet quality of free ranging cattle. J. Range Manage. 45:238-244.

Mott, G. 0. 1960. Grazing pressure and the measurement of pasture production. p. 606-611. Proc. VIII Grassland Congress, Reading, United Kingdom.

Penning, P. D. 1985. Some effects of sward conditions on grazing behaviour and intake by sheep. p. 219-226. In: O. Gudmundsson (ed.). Grazing Research at Northern Latitudes.lenum Press, New York.

Phillips, W. A. and S. W. Coleman. 1995. Productivity and economic return of three warm season grass stocker systems for the Southern Great Plains. J. Prod. Agr. 8:334-339.

Sandland. R. L. and R. J. Jones. 1975. The relation between animal gain and stocking rate in grazing trials: and examination of published theoretical models. J. Agr. Sci., Camb. 85:123-128.

SAS Institute Inc. 1990. SAS/STAT ${ }^{\mathrm{TM}}$ Users Guide. Version. 6, Fourth Ed., Vol. 2, SAS Institute, Inc., Cary, N.C.
Seman, D. H., L. D. Parsch, O. J. Loewer, M. H. Frere and H. D. Scott. 1995. GRAZEDEP data entry. p. 20-69. In: L. D. Parsch and O. J. Loewer. (ed.). GRAZE beef-forage simulation model:User guide. Southern Cooperative Series Bull. 381a., Fayetteville, Ark.

Smith, E. M. and O. J. Loewer. 1983. Mathematical logic to simulate the growth of two-perennial grasses. Transactions of ASAE 26:878883.

Stobbs, T. H. 1973a. The effect of plant structure on the intake of tropical pastures. I. Variation in the bite size of grazing cattle. Aust. J. Agr. Res. 24:809-819.

Stobbs, T. H. 1973b. The effect of plant structure on the intake of tropical pastures. II. Differences in sward structure, nutritive value, and bite size of animals grazing Setaria anceps and Chloris gayana at various stages of growth. Aust. J. Agr. Res. 24:821-829.

Taliaferro, C. M., J. R. Harlan and W. L. Richardson. 1972. Plains bluestem. Okla. Exp. Sta. Bull. B-699. 11 p.

Taliaferro, C. M., F. P. Horn, R. M. Ahring, and D. L. Weeks. 1984. Yield and quality of caucasian and Plains bluestem grasses as affected by clipping interval. Agron. J. 76:769-772.

$t^{\prime}$ Mannetje, L. and J. P. Ebersohn. 1980. Relations between sward characteristics and animal production. Trop. Grassld. 14:273-280.

Vickery P. J., and G. R. Nicol. 1982. An improved electronic capacitance meter for estimating pasture yield. Construction details and performance tests. Anim. Res. Lab. Tech. Paper No. 9. Commonwealth Sci. and Indust. Res. Organ., Australia.

Vickery. P. J., I. L. Bennett and G. R. Nicol. 1980. An improved electronic capacitance meter for estimating herbage mass. Grass and Forage Sci. 35:247-252.

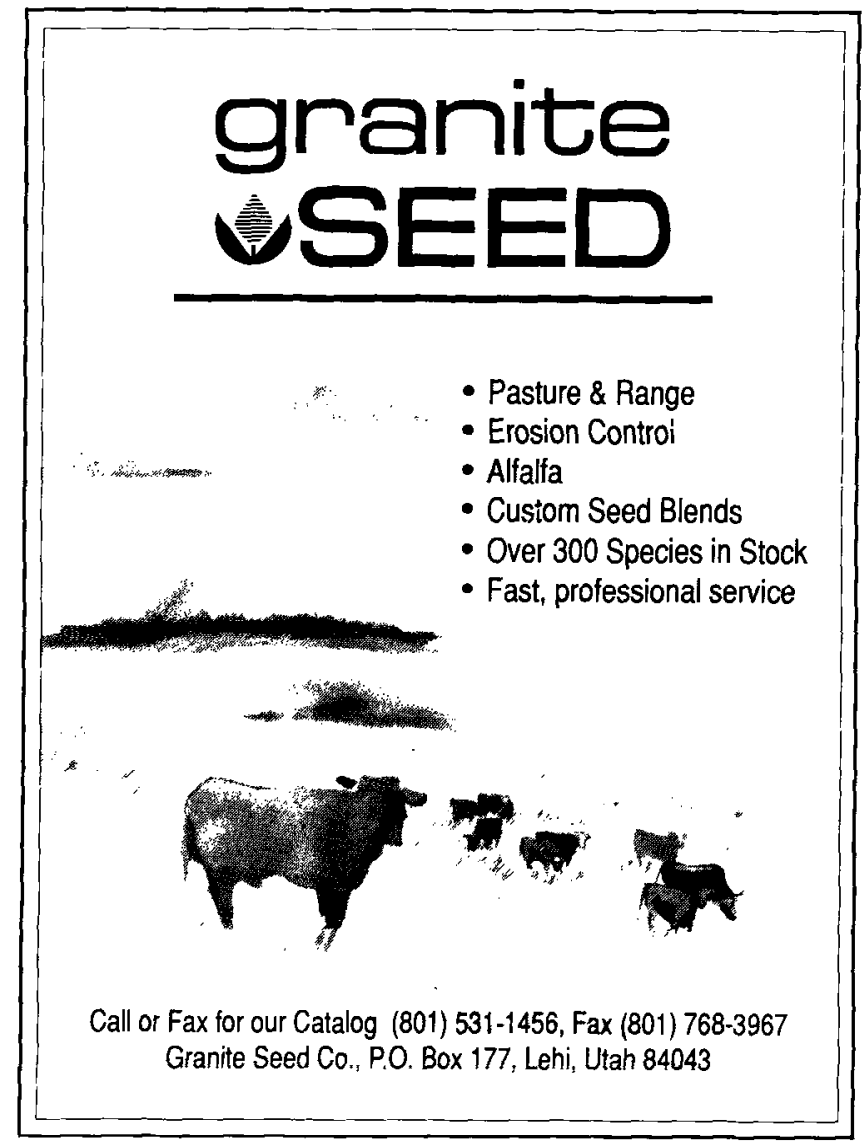

